\title{
A MEDIAÇÃO NA RESOLUÇÃO DE CONTROVÉRSIAS: OS PRINCÍPIOS INERENTES Â MEDIAÇÃO PREVISTOS NA LEI N.13.140/2015 COMO MEIO DE ACESSO À JUSTIÇA ${ }^{1}$
}

\section{RESUMO:}

\author{
Manoel Ferreira Ramos ${ }^{2}$ \\ Cassius Guimarães Chai ${ }^{3}$ \\ Vitor Hugo Souza Moraes ${ }^{4}$
}

Problematiza-se a aplicabilidade dos princípios da mediação previstos na Lei 13.140/2015 no exercício da consensualidade consoante aos impactos metodológicos como efetivo acesso à justiça. Parte-se que reconhecem a mediação como meio de resolução de conflitos. Como objeto, o exercício dos princípios da mediação no acesso à justiça. No resultado, a mediação como meio adequado de solução de conflitos. Marco teórico em Cappelletti e Chai. Nas considerações, que a autocomposição apoia-se na adesão do jurisdicionado e na obediência aos seus princípios que norteiam o procedimento.

Palavras-chave: Conflito. Poder Judiciário. Mediação. Princípios. Crise de Hegemonia.

\section{MEDIATION IN DISPUTE RESOLUTION: THE PRINCIPLES INHERENT TO MEDIATION PROVIDED FOR IN LAW 13.140/2015 AS A MEANS OF ACCESS TO JUSTICE}

\begin{abstract}
:
The applicability of the principles of mediation provided for in Law 13.140/2015 is problematized in the exercise of consensuality according to the methodological impacts as effective access to justice. It starts that recognize mediation as a means of conflict resolution.
\end{abstract}

\footnotetext{
1 Trabalho desenvolvido no âmbito no âmbito do Grupo de Ensino, Pesquisa e Extensão Cultura, Direito e Sociedade (DGP/CNPq/UFMA), sob a coordenação do professor Doutor Cassius Guimarães Chai.

${ }^{2}$ Mestrando em Direito e Instituições do Sistema de Justiça pela Universidade Federal do Maranhão (UFMA). Especialista em Teoria e Prática da Decisão Judicial pela Escola da Magistratura do Maranhão (ESMAM). Graduado em Direito pela Universidade Ceuma (UNICEUMA). Analista Judiciário do Tribunal de Justiça do Maranhão (TJMA). Mediador e conciliador judicial (CNJ). Instrutor do Curso de Formação de Mediadores e Conciliadores Judiciais (ESMAM/ENFAM). Membro do Grupo de Ensino, Extensão e Pesquisa Cultura, Direito e Sociedade (DGP/CNPq/UFMA). E-mail: manol.ramos@discentes.ufma.br. Lattes: http://lattes.cnpq.br/7802086340720852. Endereço postal: Rua 03, Quadra 12, n. 11, Planalto Vinhais II, São Luís/MA, CEP: 65074-879.

${ }^{3}$ Doutor em Direito pela Universidade Federal de Minas Gerais (UFMG) e pela Cardozo School of Law-Yeshiva University. Mestre em Direito pela Universidade Federal de Minas Gerais (UFMG). Graduado em Direito pela Universidade Federal do Maranhão (UFMA). Membro do Ministério Público do Estado do Maranhão. Professor Associado da Universidade Federal do Maranhão (UFMA) e Professor Permanente PPGD/FDV. Coordenador do Grupo de Ensino, Pesquisa e Extensão Cultura, Direito e Sociedade (DGP/CNPq/UFMA). E-mail: cassius.chai@ufma.br. Lattes: http://lattes.cnpq.br/7954290513228454. Endereço postal: Rua Juritis, n. 904, Ed. Domuns, Renascença II, São Luís/MA, CEP: 65075-249.

${ }^{4}$ Mestrando em Direito e Instituições do Sistema de Justiça pela Universidade Federal do Maranhão (UFMA). Assessor de Políticas Públicas do Instituto Sociedade, População e Natureza. Especialista em Direito Público. Docente Externo da UFMA. Membro do Grupo de Ensino, Pesquisa e Extensão Cultura, Direito e Sociedade (DGP/CNPq/UFMA). E-mail: hugo.vitor@ufma.br. Lattes: http://lattes.cnpq.br/7305075206820876. Endereço postal: Avenida dos holandeses, 03, Quadra 30, Ed. Portal da Enseada, apartamento 1002, Ponta d'Areia. São Luís/MA, CEP: 65077-357.
} 
As an object, the exercise of the principles of mediation in the access to justice. In the result, mediation as an adequate means of conflict resolution. Theoretical framework in Cappelletti and Chai. In the considerations, that the self-composition is based on the adhesion of the jurisdictional and in the obedience to its principles that guide the procedure.

Keywords: Conflict. Judicial Power. Mediation. Principles. Crisis of Hegemony.

\section{INTRODUÇÃO}

A disputa naturalmente faz parte da vida. No entanto quando uma sociedade não prestigia nem fomenta uma cultura de paz, tem como reflexo de sua mentalidade litigiosa, competitiva, segregacionista e absurdamente desigual, um Poder Judiciário, identificado como único desembargo de Justiça e seu acesso imediato, abarrotado de questões, em regra, simplórias facilmente solucionáveis pelas próprias partes por meio de tratativas autocompositivas. Destarte, houve incentivo e lugar às práticas por uma cultura de paz, uma melhor adequação de recursos humanos e econômicos na esfera pública, o que viabilizaria atividades de servidores, defensores públicos, membros do Ministério Público e magistrados em demandas que somente a seara litigiosa mais complexa e técnico-jurídico pode elucidar.

Vislumbra-se que o quantitativo latente de processos judiciais, comprovado anualmente pelos dados do Relatório Justiça em Números ${ }^{5}$, reflete um desfuncionamento entre a quantidade de ações judiciais e a baixa efetividade na resposta da Justiça em um prazo razoável ou adequado, o que deixa de cumprir um retorno satisfatório imediato ou mediato ao jurisdicionado, consolidando, assim, a morosidade processual.

Diante do entrave burocrático, característico da administração pública, vê-se o cidadão e as instituições dos sistemas de justiça envoltos em um caminho cujas margens se estreitam inevitavelmente em direção à necessidade de respostas precisas para mitigar a pretensão do indivíduo ao cumprimento da apreciação do Judiciário às lides suscitadas.

Destoante do senso comum, o magistrado encontra-se vinculado ao princípio da inafastabilidade da jurisdição, previsto na Carta Magna, artigo $5^{\circ}, \mathrm{XXXV}$, no catálogo de direitos e garantias fundamentais ou cláusula do acesso à justiça, em que "a lei não excluirá da

\footnotetext{
${ }^{5}$ Publicado desde 2003, o relatório Justiça em Números se encontra atualmente em sua $18^{a}$ edição e é elaborado com base na missão prevista na Lei n. 11.364/2006, que cria o Departamento de Pesquisas Judiciárias dentro da estrutura do Conselho Nacional de Justiça. A lei elenca como objetivos institucionais o desenvolvimento de pesquisas destinadas ao conhecimento da função jurisdicional brasileira, a realização de análise e diagnóstico dos problemas estruturais e conjunturais dos diversos segmentos do Poder Judiciário e o fornecimento de subsídios técnicos para a formulação de políticas judiciárias. (BRASIL, 2021).
} 
apreciação do Poder Judiciário lesão ou ameaça a direito" (BRASIL, 1988), devendo ser entendido, no entanto, como apreciação de causas complexas ou de direitos indisponíveis, nas quais o juiz é único legitimado a decidir.

Claro que quanto às causas de pedir, reiterada e correntemente vêm-se judicializada relações de serviços de comunicação, bancários, e prestados por concessionarias que atuam no interesse público, e a própria fazenda pública, na representação dos governos locais, regionais e da União, e, conflitos por outras relações de consumo.

A mediação merge no contexto de uma Justiça premida e constrangida pelo seu inegável desfuncionamento e estrangulamento de sua capacidade de responder à sanha de uma sociedade litigiosa e que, pela cordialidade brasileira, quer encontrar jeitinho em tudo. A mediação, portanto, está pensada para resolução de disputas, orientada por um caráter informal, célere, menos oneroso, versátil e participativo, com os imediatamente evolvidos na tensão pontual e conjuntamente, sob a condução de um facilitador, que devem realizar abertamente tratativas com o fim de encontrar um desenlace satisfatório à controvérsia que os vincula (BACELAR; LAGRASTA, 2016).

Desse modo, é pertinente conhecer os princípios que regem a mediação, conforme a Lei n. 13.140/2015 (Lei de Mediação), da imparcialidade do mediador, da isonomia entre as partes, da oralidade, da informalidade, autonomia da vontade das partes, da busca do consenso, da confidencialidade e da boa-fé.

Como problema, pretende-se verificar a aplicabilidade desses princípios, no exercício da mediação, a partir das leis e resoluções supramencionadas, no que tangem seus impactos metodológicos, reconhecidos como efetivo acesso à Justiça.

A título de hipótese, considera-se que o aparato legislativo possibilita o reconhecimento da mediação como meio de resolução de conflito capaz de trazer às partes a confiança no procedimento, diminuindo custos e evitando desgastes, promovendo o acesso à Justiça de maneira satisfatória.

Consoante ao marco teórico utilizou-se as lições de Cappelletti e Garth (1988), para tratar do acesso à justiça; Chai (2021) e Watanabe (2016) acerca da aplicabilidade dos meios adequados de resolução de conflitos, dentre outros, que foram fundamentais na conceituação de acesso à Justiça e na identificação dos obstáculos à validação dos meios autocompositivos.

Baseou-se na pesquisa teórica de revisão bibliográfica impressa e on-line pertinente ao tema como subsídio na abordagem do cenário atual pelo qual passa a mediação. 
O método utilizado foi o dedutivo, condensando-se em pesquisas às obras dos vários autores que serviram de fonte ao estudo em comento.

\section{O CONFLITO E OS MEIOS CONSENSUAIS DE SOLUÇÃO DE CONTROVÉRSIAS}

Dentre as características que permeiam as relações sociais nenhuma é tão presente quanto o conflito. Em regra, adquire conotação negativa, contudo, para o fiel desenvolvimento social deve ser enfrentado e estimulado.

Nessa acepção, a controvérsia deve ser compreendida como um caminho necessário ao crescimento individual e coletivo, afastando-se da concepção pejorativa de desavença e tendo uma inclinação positiva, como sendo uma forma de melhor compreender as relações humanas.

Diferente da heterocomposição, onde a disputa geralmente enverada na busca de quem está certo ou está errado, quem será o vencedor e o perdedor do embate, a autocomposição se constrói com a união de esforços entre pessoas que buscam o mesmo objetivo, quer seja, a resolução da controvérsia com o mínimo de desgaste possível.

Os meios adequados de resolução de conflitos corroboram para que o jurisdicionado perceba o processo judicial como alternativa posterior à tentativa amigável, afastando, assim, a tutela jurisdicional como principal meio de conduzir as pessoas à ordem jurídica correta ou justa.

Conforme leciona Coura e Chai (2014, p. 8).

\footnotetext{
Outros caminhos também buscam essa mesma solução, por exemplo, a "sumarização" do procedimento e o microssistema do processo coletivo. Todavia, nenhum desses consegue ser tão efetivo quanto a mediação, uma vez que os próprios litigantes se debruçam sobre seus interesses e pontos de convergência (COURA; CHAI, 2014, p. 8).
}

Com esse propósito, a Política Nacional de Tratamento Adequado dos Conflitos de Interesses, advinda com a Resolução 125, de 29 de novembro de 2010, do Conselho Nacional de Justiça (CNJ), dando relevância para a conciliação e a mediação, vislumbra a atualização do acesso à justiça, como acesso à ordem jurídica justa, com fomento aos mecanismos alternativos de resolução de conflitos, como a mediação e a conciliação (MORAES; SAUAIA, 2014). 
De igual modo, a Lei n. 13.105/2015 denota a importância da autocomposição com ênfase na Administração Pública, como especifica seu preâmbulo e, sobretudo, seu artigo 174, ao prever que:

Art. 174. A União, os Estados, o Distrito Federal e os Municípios criarão câmaras de mediação e conciliação, com atribuições relacionadas à solução consensual de conflitos no âmbito administrativo, tais como:

I - dirimir conflitos envolvendo órgãos e entidades da administração pública;

II - avaliar a admissibilidade dos pedidos de resolução de conflitos, por meio de conciliação, no âmbito da administração pública;

III - promover, quando couber, a celebração de termo de ajustamento de conduta. (BRASIL, 2015).

Em sua abrangência, a mediação tem por função precípua perceber os reais interesses por detrás das questões trazidas e, para tanto, o mediador, por meio de técnicas inerentes ao método, deve observa-los para que as partes encontrem a solução da divergência apontada. $\mathrm{O}$ acordo não é o objetivo soberano da metodologia e sim a concretude da comunicação entre os interlocutores.

\footnotetext{
O foco principal da mediação não está na celebração de um acordo que ponha termo ao conflito, mas em possibilitar uma reflexão detida sobre as circunstâncias do conflito, sobre as necessidades das pessoas envolvidas e o restabelecimento do canal de comunicação interrompido pela disputa. Ainda que as partes não transijam, o procedimento terá sido exitoso. (COURA; CHAI, 2014, p. 57).
}

Tal metodologia, fortalecida no texto constitucional, leis especiais e resoluções deverá ser, conforme $\$ 3^{\circ}$ do artigo $3^{\circ}$ do $\mathrm{CPC} / 2015$, "estimulada por juízes, advogados, defensores públicos e membros do Ministério Público, inclusive no curso do processo judicial" (BRASIL, 2015).

É importante frisar que a aplicação da mediação como meio adequado na resolução de disputas representa um avanço, haja vista a decisão judicial guardar grande simbolismo quanto à segurança jurídica, mas que precisa ser aperfeiçoamento, em razão da sua constante evolução.

Diante do cenário que se apresenta o Poder Judiciário, e da necessidade de mudança de paradigma, de uma tradição litigiosa para um modelo em que a solução de conflitos seja pautada em ambiente pacífico, é inegável, portanto, a contribuição da mediação para a sociedade e para as instituições do sistema de justiça, principalmente ao Poder Judiciário. 


\section{A MEDIAÇÃo COMO DE MEIO DE RESOLUÇÃO DE CONFLITOS}

Embora o acesso à justiça constasse, ainda que com menor força, nas constituições de 1934 e de 1946, na Carta de 1988, tal garantia pôde ser observada não apenas como o direito de ingressar em juízo, mas perspectiva de uma prestação jurisdicional eficaz e célere. Porém, é perceptível que, apesar de disposto no artigo $5^{\circ}$, inciso LXXVIII do texto Constitucional o princípio da razoável duração do processo, o que se verifica são processos que demoram anos sem qualquer resposta.

Os anos de 1970, quando o direito clássico legitimava apenas o juiz togado como terceiro julgador, para a prolação da sentença de mérito havia apenas o modelo da heterocomposição na resolução de conflitos, sem qualquer participação dos litigantes na solução da contenda no que se refere à decisão judicial.

A esse respeito, Chiovenda (2000) descreve o juiz que atuava conforme a vontade da lei: o magistrado a elaborava e a aplicava. A lei era seu próprio fim. Não tinha função de atuar em prol do bem comum, bastando o exercício do magistrado em utilizá-la. Esse pensamento angariou adeptos como Calamandrei (1973) e Passos (2014), assim como críticos a exemplo de Lacerda (2008), com a argumentação de que o juiz possuía apenas função legiferante e sem que o resultado da aplicabilidade da lei tivesse qualquer importância para o Judiciário.

Nesse contexto histórico, existe a doutrina de Carneluti (2000) com a clássica conceituação da lide como o conflito de uma pretensão resistida, significando que a função do judicante é a composição da lide, em que o julgador cria a norma individual para o caso concreto. Como crítica à teoria, surgiu a tese de que estaria contrária ao Estado Constitucional, por defender a ideia de supremacia da lei sem considerar a compreensão do caso em si quando do julgamento.

Com os anos de 1980 vieram as primeiras inserções de métodos adequados de solução de conflitos, tendo como marco a obra de Capeletti e Garth (1988), "Acesso à Justiça", com ideias sobre garantir a tutela jurisdicional de maneira mais abrangente e gratuita, tornando possível o acesso da via processual às camadas mais pobres. Assim como, a importância do advogado pago pelo Estado aos desprovidos de recursos financeiros e a visibilidade dos problemas envolvendo os direitos difusos. 
Essa teoria apontou que apenas o procedimento comum não bastava como forma de resolução de conflitos, uma vez que as partes ficavam engessadas perante a figura do juiz, ainda que se tratasse de questões sem qualquer complexidade, além do que, não havia participação direta dos envolvidos no processo.

Com isso, o legislador começou a entender que seria mais plausível às partes decidir qual o procedimento que queriam se submeter no que se refere ao julgamento das desavenças, não sendo obrigadas à submissão ao procedimento comum, até então soberano.

Surge nesse momento ideias sobre instrumentos de ampliação do acesso à justiça de maneira eficaz, garantindo maior participação das partes no processo e a redução da judicialização, originando assim, o que ficou conhecido como Tribunal Multiportas ${ }^{6}$.

Esse sistema ganhou notoriedade com a vigência do Código de Processo Civil de 2015, posto atender à garantia constitucional trazida no artigo $5^{\circ}, \mathrm{XXXV}$, o que trouxe empoderamento às partes, tirando-as da condição de expectador para efetivo participante na escolha não só do procedimento a ser adotado, mas também, influenciando diretamente na decisão almejada.

O que fomenta a mudança de uma cultura do litígio para a pacificação social (WATANABE, 2016), somada à economia de recursos dispensados ao processo judicial com vistas a evitar desgastes com a demora da decisão, resultando na possibilidade de resolução de questões por meio de acordo judicial ou extrajudicial com participação ativa dos envolvidos, alcançados a partir do incentivo proporcionado pelo Código de Processo Civil de 2015, Lei n. 13.140/2015 (Lei de Mediação) e Resolução n. 125/2015 do CNJ. Institutos fundamentais para uma nova forma de olhar, analisar, discutir e resolver o conflito.

De modo a somar elementos para a construção do cenário propício à Política Judiciária Nacional no tratamento adequado de conflitos como garantia de acesso à ordem jurídica justa, de forma efetiva, tempestiva e adequada. (WATANABE, 2016).

\footnotetext{
${ }^{6}$ A expressão "Justiça Multiportas" foi cunhada pelo professor Frank Sander, da Faculdade de Direito de Harvard. Opondo-se ao sistema clássico, que antevê a atividade jurisdicional estatal como a única capaz de solver conflitos, o Sistema de Justiça Multiportas remete a uma estruturação que conta com diferentes mecanismos de tutela de direitos, sendo cada método adequado para determinado tipo de disputa. A jurisdição estatal, nessa senda, passa a ser apenas mais uma dentre as diversas técnicas disponíveis. Ressalta-se que optar pelo caminho do Sistema de Justiça Multiportas não é uma peculiaridade do Estado brasileiro. Após a Segunda Guerra Mundial, diversos países têm atualizado seus sistemas jurídicos nesse sentido, objetivando maior respeito e proteção aos direitos humanos, individuais e coletivos. (COÊLHO, 2020).
} 
Sua visibilidade foi verificada não somente como uma alternativa viável para diminuir o número de processo e recursos diuturnamente interpostos perante o Judiciário em todas as instâncias, mas, como ferramenta necessária para uma real mudança de cultura. Tendo essa transformação galgada pela forma como são vistos, aceitos e, sobretudo, utilizados os meios adequados de solução de conflitos.

No entanto, mesmo diante de um cenário adaptado à realidade dos meios adequados para a solução de demandas, ainda está longe de se vivenciar a prestação jurisdicional ideal, em que um dos principais embargos é a chamada "cultura da sentença" (WATANABE, 2016, p. 51), que traz como consequência o aumento de recursos congestionando as instâncias ordinárias e superiores, assim como fortalecendo o número de execuções judiciais.

\section{OS PRINCÍPIOS NORTEADORES DA MEDIAÇÃO NA LEI N. 13.140/2015 (LEI DE MEDIAÇÃO)}

No ordenamento jurídico, os princípios são reconhecidos como as bases de sustentação que orientam a interpretação e aplicabilidade da norma, de maneira que os atores compreendam como cada instituto deve ser posto em prática, da forma mais adequada possível.

Em se tratando dos meios adequados de resolução de conflitos, por se tratar de uma inovação com natureza informal e flexível, acaba por gerar perante um sistema historicamente litigioso, desconfiança e incredibilidade, não somente do jurisdicionado, que encontra no decisum a comodidade de apenas cumprir a imposição do terceiro togado, bem como do próprio magistrado, bitolado a julgar com vistas a reduzir números e produzir relatórios, em que a autocomposição aparenta ser elemento estranho que o distancia da promoção na carreira por produtividade ou merecimento.

De modo que, aparentemente possam demonstrar distinções gritantes, o procedimento da mediação guarda semelhança estrutural com o processo judicial, em que é possível situar ambas as formas de solução de conflitos no mesmo plano e visualiza-las sob o prisma da teoria geral do processo, posto que partilhem da mesma preocupação no que pertine a cuidarem de processos instrumentais a serviço da pacificação social (GABBAY, 2011).

Além do que, obedecem a princípios parecidos já que tratam das resolubilidades de demandas, cujas diferenças encontram-se no campo da atuação do terceiro e na participação 
dos envolvidos no processo, assim como as relações de poder possuem suas particularidades como dispostas no CPC/2015, Lei de Mediação e Resolução n. 125/2010 do CNJ.

Gabbay (2011, p. 23) desenvolve a argumentação de que também no procedimento da mediação existem relações de poder, procedimentos, princípios, valores e garantias que precisam necessariamente ser sistematizados. "Isso principalmente quando a mediação é institucionalizada, como ocorre no ambiente judicial, havendo regulação do processo e coercibilidade do acordo".

No entanto, diverso do pensamento da autora citada, a autocomposição permite que as realizem suas tratativas de forma livre e desvinculadas à formalização do acordo. Não há obrigatoriedade e sim voluntariedade. Tanto que, caso o terceiro facilitador perceba que uma das partes encontra-se sem advogado e verifica que isso possa prejudica-la tem o poder-dever de suspender a audiência para que ambas estejam em iguais condições de negociação.

Existe uma série de exigência a serem atendidas pelos atores do procedimento da mediação para que os atos inerentes desde a audiência até a homologação judicial sem válidos e para isso se faz necessário compreender os princípios norteadores da metodologia para garantir o grau de confiabilidade esperada pelo jurisdicionado, a fim de que ao formalizar um acordo, que seja por livre vontade das partes, uma vez que são esses os protagonistas da cultura da pacificação social.

O rol de princípios contidos na Lei de Mediação, dispostos no artigo $2^{\circ}$, diferencia-se um pouco do disposto na Resolução n. 125/2010 do CNJ, no artigo $1^{\circ}$ do Anexo III, onde está o Código de Ética de Conciliadores e Mediadores Judiciais, bem como o trazido no Código de Processo Civil de 2015, em seu artigo 166, porém, assim com os demais diplomas, buscou elencar as bases para que o procedimento autocompositivo pudesse gozar de todas as competências para torna-lo capaz de assumir um espaço efetivo na resolução de demandas.

Nesse sentido, o princípio da imparcialidade do mediador se traduz como o dever de agir com ausência de favoritismo, preferência ou preconceito, assegurando que valores e conceitos pessoais não interfiram no resultado do trabalho, compreendendo a realidade dos envolvidos no conflito e jamais aceitando qualquer espécie de favor ou presente; o princípio da isonomia entre as partes tem como objetivo contribuir para um desfecho harmônico entre as partes, em que o mediador deve ter o cuidado em tratar as partes de forma equânime, proporcionando a ambas os mesmos de critérios de participação e as mesmas oportunidades. 
O princípio da oralidade informa que as negociações feitas na sessão deverão ser orais e sem regras formais; o principio da informalidade estabelece que a negociação posta oralmente deva ser livre de formalidade, visto que a formalidade poderia constranger os participantes; o princípio da autonomia da vontade das partes revela que quem tem o poder de resolver a questão são as pessoas envolvidas na situação apresentada, em que a decisão final cabe às partes, livre de qualquer coação; o princípio da busca do consenso tem como pressuposto a autonomia dos envolvidos em relação às decisões sobre as questões que envolvem o conflito, cabendo às partes a escolha do que for melhor com resolução da contenda.

O princípio da confidencialidade determina ao mediador o dever de manter sigilo sobre todas as informações obtidas na sessão, com exceção daquelas em que as partes autorizaram expressamente, ou que viole a ordem pública e às leis vigentes. Por fim, o princípio da boa-fé tem por escopo a confiança quanto ao uso das informações e dos conhecimentos adquiridos durante o procedimento.

Com base nesses princípios, fica claro que não há espaço para desconfianças do jurisdicionado ou mesmo de magistrados ou outros atores envolvidos na seara conciliatória, quanto à regularização adstrita à mediação.

Reforçando, assim, tal desmistificação, o Código de Processo Civil de 2015, Lei de Mediação (Lei n. 13.140/2015) e Resolução n. 125/2015 do CNJ trouxeram inserção dos princípios norteadores da mediação, imbuídos no fortalecimento e disseminação do método autocompositivo, submetidos não só aos princípios gerais do direito, mas aos seus princípios próprios.

Destarte, a pesquisa em apreço trouxe o rol de princípios contido no artigo $2^{\circ}$, da Lei n. 13.140/2015, constando os princípios da imparcialidade do mediador, da isonomia entre as partes, da oralidade, da informalidade, da autonomia da vontade das partes, da busca do consenso, da confidencialidade e da boa-fé. Tal arcabouço formaliza e disciplina a função dos aplicadores da metodologia.

A existência do Princípio da Imparcialidade tem por razão a total abstenção do mediador quanto à produção da resposta diante da lide vivenciada pelas partes. Os envolvidos por meio das tratativas direcionadas pelo facilitado com o estímulo à comunicação respeitosa e aberta, naturalmente, devem-se perceber como trilhadores do mesmo caminho, onde não há vencedores ou perdedores, nem o "eu contra ele" e sim o "eu e ele". 
As partes precisam ver "para" e não "o" problema de forma isolada, afastando-o da pessoa que o personifica. E para isso ser possível, o mediador deve manter-se acima das partes e em igual distância (não somente física) entre elas, para ouvi-las igualmente, isentando-se de influenciar na construção da solução, exercitando a escuta ativa.

$\mathrm{Na}$ obediência a esse princípio, o terceiro dever ater-se às questões que envolvem o conflito, por meio dos relatos estimulados com as técnicas de capacitação, evitando que as discussões se afastem do ponto controverso, objetivando, assim, perceber os interesses explícitos e implícitos, devolvendo de modo não violento às partes o que fora exposto, levando-as à reflexão acerca do que pode ser vislumbrado como resposta.

Nos dizeres de Zárate (2014, p. 43) "La imparcialidad por su parte es un deber que se refiere a la persona o las personas responsables de facilitar la negociación entre las partes". Desse modo, o mediador deve ter como norte seu papel transformador, a partir da atuação imparcial, em que terá a oportunidade de aplicar as técnicas pertinentes a cada caso, sendo um multiplicador da consensualidade.

Por sua vez, o Princípio da Isonomia (ou Horizontalidade) visa à igualdade material concretizada em uma justiça que garanta tratamento equilibrado para os interlocutores, consoante às distinções naturais existentes nas relações sociais e econômicas, com vistas à restauração do equilíbrio entre as partes, concedendo participação efetiva no processo aos envolvidos.

Destarte, a postura do mediador é transformar um ambiente passível de desequilíbrio em que uma parte poderia se sobrepujar à outra, em razão de realidades distintas, em um espaço de equidade em que as partes possam sentir-se no mesmo plano horizontal.

O princípio da horizontalidade é caracterizado como a inexistência de hierarquia entre os protagonistas do conflito, bem como entre estes e o mediador responsável por conduzir as atividades, a fim de possibilitar a construção de um acordo que seja resultado dos direitos pertencentes a cada uma das partes e não da sucumbência da parte mais fraca perante a parte mais forte e preparada. (COSTA; LINDOSO, 2014, p. 270).

Nesta perspectiva, a mediação busca promover o equilíbrio entre os "gêneros, na medida em que ambos possuem as mesmas oportunidades dentro do procedimento" (COSTA; LINDOSO, 2014, p. 188).

Com relação ao Princípio da Oralidade tem a particularidade de tornar possível o entendimento entre as partes, em uma relação mutua e madura, por meio do diálogo aberto e 
franco. Na conversação, os participantes podem mostrar o que os está incomodando e o que pretendem com a audiência. É o instrumento do qual dispõe a mediação para aproximar as partes, por meio do entendimento, da questão que eventualmente os afastou.

Infere-se assim, que a oralidade tem por base facilitar a comunicação entre as partes, para que haja a compreensão dos interesses dos envolvidos e para que assim, o mediador possa, por meio das técnicas pertinentes, extrair informações necessárias para tornar as partes capazes de vislumbrar a melhor solução para a contenda apresentada.

Pela fala é possível perceber elementos que no decorrer das sessões se tornam indispensáveis para a construção da solução necessária para a questão trazida. Em sendo uma característica tão própria do ser humano, a oralidade tem seu papel essencial na mediação, por possibilitar que a comunicação aconteça compreensivamente a todos os envolvidos.

Dando seguimento, não obstante, a existência de certo grau de formalidade no procedimento da mediação, esta deve ser mitigada, longe de ser exacerbada, de modo a dificultar a prestação jurisdicional, é nessa direção que o Princípio da Informalidade, na autocomposição, favorece o resultado pretendido.

A ideia é tornar o ambiente leve, isento da rigidez e burocracia pertinentes à heretorocomposição, onde a dinamicidade não permita que a o zelo com a formalidade seja mais importante que o entendimento entre as partes.

O que existe não é o afastamento completo da formalidade, posto que esteja presente de forma mais branda, mas o exercício de uma metodologia cujos atos praticados são calcados com precisão, clareza, concisão e simplicidade, em um contexto lógico, de tal forma que atenda às necessidades dos envolvidos.

A metodologia possui seu conjunto de normas próprio que atende ao procedimento de maneira eficaz. Isso porque, o método extrajudicial proposto possibilita que determinados trâmites sejam suprimidos ou modificados, para torná-lo mais dinâmico e menos burocrático, dando maior fluidez ao bom desenvolvimento do processo.

Soma-se ao procedimento, o Princípio da Autonomia da Vontade das Partes, cuja função é deixar claro o protagonismo dos interlocutores na mediação, cabendo a eles a decisão de participar ou não do ato, assim como a construção dos termos que irão compor o registro material da audiência.

Como assevera Chai e Castro (2014, p. 84), 
[...] a caracterização da mediação como expressão da autonomia da vontade das partes interessadas e ou envolvidas em um determinado conflito, possibilitando-se lhes compreender o contexto de seu conflito, e dele retirarem e ou identificarem alternativas de beneficio-mútuo.

As partes podem dispor livremente, desde que não contrariem a ordem pública, sobre a questão de divergência, sendo que estas devem ser conscientes de suas responsabilidades com os resultados da decisão que apontaram como melhor opção e, pelo próprio andamento do procedimento da mediação, até a sua conclusão.

Pelo Princípio da Busca do Consenso as partes têm total autonomia de decidir a busca pelo acordo e, consequentemente, a não impetração ou o fim do processo. No entanto, existem questões cuja conclusão foge da autocomposição, sendo realmente exigível a decisão prolatada para pôr fim ao processo.

Desse modo, "a mediação implica um dialogo construtivo e colaborativo, onde diferentes atores busca um consenso que implica na reflexão profunda a respeito das condutas pessoais e interpessoais na convivência social". (BONFIM; FERNANDES; BORJA, 2014, p. 292).

Assim sendo, para o consenso acontecer, é importante separar as pessoas do problema, o que consiste em atacar a divergência sem culpar o indivíduo, adotando ainda, uma postura de não adversidade, não competitividade, na procura pelo favorecimento final para a possibilidade do entendimento.

No mesmo sentido, o Princípio da Confidencialidade garante às partes que todo o exposto nas verbalizações ficará restrito ao momento da audiência, não podendo ser utilizado como prova em eventual ação, salvo se cometido crime durante a sessão.

Tem por intuito munir os litigantes de confiança no procedimento, certos de que todas as informações prestadas durante a audiência não serão publicadas, a não que a publicização aconteça por iniciativa dos interlocutores e sem utilização dos meios judiciais de divulgação.

Nas lições de Chai, Bussinguer e Santos (2014, p. 160):

Sob o princípio da confidencialidade o mediador assume o compromisso de manter as informações discutidas sob sigilo absoluto. Nada que tenha sido discutido durante a mediação será levado ao conhecimento de terceiros. O caráter privativo da mediação, a boa-fé envolvida são a base estrutural de uma mediação sólida e duradoura. 
Por meio da confidencialidade as partes acreditam não somente no mediador, mas também, em toda a estrutura dos meios de solução de controvérsia, como metodologia desenhada para que os elementos que permeiam a questão sejam postos sem medo, como que cada um dos participantes se reconheça como uma peça necessária para a realização da comunicação eficiente e tenha como objetivo o entendimento das causas da demanda e a possível solução.

Para concluir a parte dos princípios relacionados na Lei de Mediação, tem-se o Princípio da Boa-Fé, como aquele primordial para que a mediação tenha sentido, pois, de nada adiantaria as partes discorrerem sobre os pontos relevantes de uma questão, perante o mediador, sem que a boa-fé estivesse norteando todo o procedimento, em um pressuposto de confiabilidade.

É o princípio que representa a harmonia na comunicação entre as partes, quando comprova que ambos estão dispostos a lidar de maneira aberta com a questão e suas eventuais consequências. Por esta razão, é imprescindível que as partes estejam optando pela mediação de boa-fé, de maneira livre e conduzam todo o processo nessa perspectiva, uma vez que lhes cabe o maior interesse em ver concretamente a realização do entendimento.

Desse modo, a boa-fé como garantia constitucional investe de legitimidade o procedimento da mediação, tornando claro e confiável o ambiente protegido legalmente. Não dando margem para qualquer pretensão de diminuir sua validade no campo judicial e extrajudicial.

Nesse sentido, o que essa legislação confirma é a importância da cooperação na mediação como ferramenta que traduz o comprometimento dos envolvidos para validar o método. Para que antes de tentar buscar a resolução de uma controvérsia, se procure primeiramente a tratativa amigável e consensual, deixando a judicialização como ultima ritio para a contenda.

\section{CONSIDERAÇÕES FINAIS}

Em decorrência das transformações sociais, sobretudo no que guarda relação com as respostas às controvérsias, a decisão judicial não atende as demandas processuais dentro de um lapso temporal satisfatório e nem como garantia de que as partes deixarão de retornar ao Judiciário para tratar da mesma causa ou algo adjacente a ela. 
O terreno jurídico precisou e precisa ainda de mudanças substanciais às necessidades postas por um jurisdicionado que encontrou nos direitos fundamentais instituídos no texto constitucional um caminho largo e abrangente de possibilidades para resolver conflitos.

Essa ampliação de direitos com vistas ao acesso à justiça alavancou-se a partir de provocações oriundas da sociedade e de instituições atentas às urgentes adequações aos anseios vigentes, das mais variadas classes sociais permeada de particularidades em diversos aspectos como, por exemplo, a autodeterminação em resolver uma divergência sem que a decisão seja imposta por um terceiro.

Atenta às efervescências coletivas, a Constituição Federal tratou de garantir como direito fundamental o acesso à Justiça, enquanto real exercício da cidadania, o que foi acompanhado pelo Código de Processo Civil de 2015 e Lei n. 13.140/2015 (Lei de Mediação), com vistas a uma prestação jurisdicional mais ágil e eficiente, transformadora do cenário de lentidão processual comprovado pela demanda excessiva nos números da Justiça brasileira, publicados pelo próprio $\mathrm{CNJ}$, deflagrando um contexto de crise, em que o Judiciário reconhece não conseguir solucionar esse colapso.

Em razão dessa inépcia, tornou-se mister pensar outras formas de resolução processual seguras e eficazes, possível com o advento da Política Judiciária Nacional de tratamento adequado de conflitos, que trouxe na autocomposição uma metodologia coerente na solução de disputas, em que as partes possuem total e plena autonomia de decisão.

Essa nova estrutura se distancia do antigo paradigma da decisão judicial, garantindo a Justiça de maneira célere, segura e econômica, o que não só ajuda os envolvidos no litígio, mas também contribui para a pacificação social e fortalecimento das instituições dos sistemas de justiça.

Insta ao Judiciário o oferecimento de caminhos paralelos que resulte na justiça prestada eficazmente, com a possibilidade de menos formalidade e mais celeridade. O que faz da mediação um instrumento extrajurídico de extrema importância para o bem social, por ser capaz de vislumbrar a justiça nos espaços que ela é cabível e de prevenir a ocorrência de novos litígios, além de fomentar a sociedade para uma cultura de paz.

Nesse ínterim, os princípios inerentes à mediação encontram importância essencial para o reconhecimento da metodologia e sua aplicabilidade, provocando uma sociedade desacostumada em resolver suas próprias questões em protagonistas da decisão. 
Os princípios norteadores solidificam a metodologia como uma nova cultura a ser vivenciada natural e positivamente. Assim, tendem a validar a essência da mediação, quando tornam o ambiente judicial, historicamente beligerante, para um espaço onde o diálogo seja a ferramenta utilizada na construção de uma solução adequada para cada caso em particular.

A mediação fortalecida nos princípios desenhados a partir de necessidades sociais que se sustentam na imparcialidade do mediador, na isonomia entre as partes, na oralidade, na informalidade, na autonomia da vontade das partes, na busca do consenso e na confidencialidade, se mostra como resposta plausível para enfrentar as ocorrências menos complexas e produzir decisões que não só ponham fim ao processo judicial, mas ao conflito por completo.

\section{REFERÊNCIAS}

ADORNO, Alberto Manuel Poletti; CHAI, Cássius Guimarães e DJEFFAL, Christian (Org.). Mediação e conflitos internacionais. São Luís: Procuradoria Geral de Justiça do Estado do Maranhão/Jornal da Justiça/Cultura, Direito e Sociedade (DGP/CNPq/UFMA). Coleção Global Mediation Rio. São Luís: Global Mediation, 2014.

BACELAR, Roberto Portugal; LAGRASTA, Valéria Ferioli (Coord.). In: Conciliação e Mediação: ensino em construção. Enfam. 2016. São Paulo: Editora Tribo.

BRASIL. Conselho Nacional de Justiça. AZEVEDO, André Gomma de (Org.). Manual de Mediação Judicial, 6. ed. Brasília/DF: CNJ, 2016. Disponível em: http://www.cnj.jus.br/files/conteudo/arquivo/2016/07/f247f5ce60df2774c59d6e2dddbfec54.p df. Acesso em: 30 jul. 2021.

BRASIL. Conselho Nacional de Justiça. Justiça em números 2021. Brasília: CNJ, 2021. Disponível em: https://www.cnj.jus.br/wp-content/uploads/2021/11/relatorio-justica-emnumeros2021-221121.pdf. Acesso em 30 nov. 2021.

BRASIL. Lei n. 13.105, de 16 de março de 2015. Institui o Código de Processo Civil. Diário Oficial da União, Brasília, DF, 17 março 2015. Disponível em: http://www.planalto.gov.br/ccivil_03/_Ato2015-2018/2015/Lei/L13105.htm. Acesso em: 30 nov. 2021.

BRASIL. Lei n. 13.140, de 26 de junho de 2015. Institui a Lei de Mediação. Diário Oficial da União, Brasília, DF. 26 de junho de 2015. Disponível em: http://www.planalto.gov.br/ccivil_03/_ato2015-2018/2015/Lei/L13140.htm. Acesso em: 21 nov. 2021. 
BONFIM, Ana Paula Rocha do; FERNANDES, Lopes, Luciana; BORJA, Rodrigues, Maria Victória Braz. Mediar UFBA: um caminho para a compreensão da indissociação entre mediação universitária e mediação comunitária. In: CHAI, Cássius Guimarães; BRAGA NETO, Adolfo; ROMANO, Michel Betenjane (Coord.). Mediação comunitária. São Luís: Procuradoria Geral de Justiça do Estado do Maranhão/Jornal da Justiça/Cultura, Direito e Sociedade (DGP/CNPq/UFMA). Coleção Global Mediation Rio. São Luís: Global Mediation, 2014.

CALAMANDREI, Piero. Estudios sobre el proceso civil. Buenos Aires: EJEA, 1973.

CARNELUTTI, Francesco. Instituições do processo civil. São Paulo: Classic Book, 2000, v.1.

CAPPELLETTI, Mauro; GARTH, Bryant. Acesso à justiça. Trad.: Ellen Gracie Northfleet. Porto Alegre: Sergio Antonio Fabris Editor, Porto Alegre, 1988.

CHAI, Cássius Guimarães; CASTRO, Alana Maria Almeida de. O sistema de justiça e a mediação em guarda familiar: desafios e perspectivas com a reforma processual civil e a proposta de Lei Federal 117/13. In: COURA, Alexandre de Castro; CHAI, Cássius Guimarães (Org.). Mediação, Sistema de Justiça e Administração Pública: o Poder Judiciário, o Ministério Público e a Advocacia Pública. São Luís: Procuradoria Geral de Justiça do Estado do Maranhão/Jornal da Justiça/Cultura, Direito e Sociedade (DGP/CNPq/UFMA). Coleção Global Mediation Rio. São Luís: Global Mediation, 2014.

CHAI, Cássius Guimarães (Org.). Mediação e relações de consumo. São Luís: Procuradoria Geral de Justiça do Estado do Maranhão/Jornal da Justiça/Cultura, Direito e Sociedade (DGP/CNPq/UFMA). Coleção Global Mediation Rio. São Luís: Global Mediation, 2014.

CHAI, Cássius Guimarães; BRAGA NETO, Adolfo; ROMANO, Michel Betenjane (Coord.). Mediação comunitária. São Luís: Procuradoria Geral de Justiça do Estado do Maranhão/Jornal da Justiça/Cultura, Direito e Sociedade (DGP/CNPq/UFMA). Coleção Global Mediation Rio. São Luís: Global Mediation, 2014.

CHAI, Cássius Guimarães; BUSSINGUER, Elda Coelho de Azevedo; SANTOS, Ricardo Goretti (Org.). Mediação e direitos humanos. São Luís: Procuradoria Geral de Justiça do Estado do Maranhão/Jornal da Justiça/Cultura, Direito e Sociedade (DGP/CNPq/UFMA). Coleção Global Mediation Rio. São Luís: Global Mediation, 2014.

CHIOVENDA, Giuseppe. Instituições de direito processual civil. Campinas: Bookseller, 2000.

COÊLHO, Marcus Vinicius Furtado. O Sistema de Justiça Multiportas no Novo CPC. 6 jul. 2020. Disponível em: https://www.migalhas.com.br/coluna/cpc-marcado/330271/osistema-de-justica-multiportas-no-novo-cpc. Acesso em: 29 nov. 2021.

COSTA, Amanda Cristina de Aquino; LINDOSO, Klécia Patrícia de Melo. Resultados desproporcionais na mediação de conflitos e a efetivação dos direitos humanos: a comunidade 
de Santa Rosa dos Pretos e a necessidade de proteger os remanescentes de quilombo. In. CHAI, Cássius Guimarães; BUSSINGUER, Elda Coelho de Azevedo; SANTOS, Ricardo Goretti. (Org.). Mediação e direitos humanos. São Luís: Procuradoria Geral de Justiça do Estado do Maranhão/Jornal da Justiça/Cultura, Direito e Sociedade (DGP/CNPq/UFMA). Global Mediation, 2014.

COURA, Alexandre de Castro; CHAI, Cássius Guimarães (Org.). Mediação, sistema de justiça e administração pública: o Poder Judiciário, o Ministério Público e a Advocacia Pública. São Luís: Procuradoria Geral de Justiça do Estado do Maranhão/Jornal da Justiça/Cultura, Direito e Sociedade (DGP/CNPq/UFMA). Coleção Global Mediation Rio. São Luís: Global Mediation, 2014.

COURA, Alexandre de Castro; CHAI, Cássius Guimarães (Org.). Mediação, Sistema de Justiça e Administração Pública: o Poder Judiciário, o Ministério Público e a Advocacia Pública. São Luís: Procuradoria Geral de Justiça do Estado do Maranhão/Jornal da Justiça/Cultura, Direito e Sociedade (DGP/CNPq/UFMA). Coleção Global Mediation Rio. São Luís: Global Mediation, 2014.

FANTILLI, Juan Martín Palacios. La mediación y su aplicación en las relaciones de consumo transfronterizas. In: Mediação e relações de consumo. CHAI, Cássius Guimarães (Org.); ZÁRATE, Aníbal (Coord.). São Luís: Procuradoria Geral de Justiça do Estado do Maranhão/Jornal da Justiça/Cultura, Direito e Sociedade (DGP/CNPq/UFMA). Coleção Global Mediation Rio. São Luís: Global Mediation, 2014.

FISHER, Roger; URY, William; PATTON, Bruce. Como chegar ao sim: como negociar acordos sem fazer concessões. 3. ed. rev. e atual. Rio de Janeiro: Solomon, 2014.

GABBAY, Daniela Monteiro. Mediação \& Judiciário: condições necessárias para a institucionalização dos meios autocompositivos de solução de conflitos. Tese de doutorado. Faculdade de Direito da Universidade de São Paulo. São Paulo, 2011. Disponível em: https://www.teses.usp.br/teses/disponiveis/2/2137/tde-24042012141447/publico/Daniela_Monteiro_Gabbay.pdf. Acesso em 28 nov. 2021.

LACERDA, Galeno. Teoria geral do processo. Imprenta: Rio de Janeiro, Forense, 2008.

MORAES, Luana Celina Lemos de; SAUAIA, Artenira da Silva e Silva. A mediação como instituto necessário para a efetividade de decisões e para a melhoria jurisdicional nas varas de família. In: CHAI, Cássius Guimarães (Org.). BAHIA, Alexandre Gustavo Melo Franco; SAUAIA, Artenira Silva e Silva; CALDAS, José Manuel Peixoto. (Coord.). Mediação familiar, infância, idoso e gênero. São Luís: Procuradoria Geral de Justiça do Estado do Maranhão/Jornal da Justiça/Cultura, Direito e Sociedade (DGP/CNPq/UFMA). Global Mediation, 2014.

PASSOS, Jose Joaquim Calmon de. Cidadania e efetividade do processo. p. 394. Todos os textos de Calmon de Passos citados neste artigo estão em Ensaios e Artigos. v. 1. Salvador: Juspodivm, 2014. 
TARTUCE, Fernanda. Mediação nos conflitos civis. Rio de Janeiro: Forense; São Paulo: Método, 2008.

ZÁRATE, Anibal. La mediación como alternativa informal en los conflictos de consumo en colombia. In: CHAI, Cássius Guimarães (Org.). ZÁRATE, Anibal (Coord.). Mediação e relações de consumo. São Luís: Procuradoria Geral de Justiça do Estado do Maranhão/Jornal da Justiça/Cultura, Direito e Sociedade (DGP/CNPq/UFMA). Global Mediation, 2014. 